\title{
Cognitive behavioral therapy in pharmacoresistant obsessive-compulsive disorder
}

\author{
This article was published in the following Dove Press journal: \\ Neuropsychiatric Disease and Treatment \\ 14 March 2016 \\ Number of times this article has been viewed
}

\section{Jana Vyskocilova' \\ Jan Prasko ${ }^{2}$ \\ Jiri Sipek ${ }^{3}$}

'Faculty of Humanities, Charles University in Prague, Prague, ${ }^{2}$ Department of Psychiatry, Faculty of Medicine and Dentistry, Palacky University Olomouc, University Hospital Olomouc, Olomouc, ${ }^{3}$ Department of Psychology, Faculty of Arts, Charles University in Prague, Prague, Czech Republic
Correspondence: Jan Prasko Department of Psychiatry, Faculty of Medicine and Dentistry, Palacky University Olomouc, University Hospital Olomouc, IP Pavlova 6, Olomouc 775 20, Czech Republic

Email praskojan@seznam.cz
Background: The aim of the study was to determine whether patients with obsessive-compulsive disorder (OCD) resistant to drug therapy may improve their condition using intensive, systematic cognitive behavioral therapy (CBT) lasting for 6 weeks, and whether it is possible to predict the therapeutic effect using demographic, clinical, and selected psychological characteristics at baseline.

Methods: Sixty-six OCD patients were included in the study, of which 57 completed the program. The diagnosis was confirmed using the structured Mini International Neuropsychiatric Interview. Patients were rated using the objective and subjective forms of the Yale-Brown Obsessive Compulsive Scale, objective and subjective forms of the Clinical Global Impression, Beck Anxiety Inventory, Beck Depression Inventory, Dissociative Experiences Scale, 20-item Somatoform Dissociation Questionnaire, and the Sheehan Disability Scale before their treatment, and with subjective Yale-Brown Obsessive Compulsive Scale, objective and subjective Clinical Global Impression, Beck Anxiety Inventory, and Beck Depression Inventory at the end of the treatment. Patients were treated with antidepressants and daily intensive group CBT for the 6-week period.

Results: During the 6-week intensive CBT program in combination with pharmacotherapy, there was a significant improvement in patients suffering from OCD resistant to drug treatment. There were statistically significantly decrease in the scores assessing the severity of OCD symptoms, anxiety, and depressive feelings. A lower treatment effect was achieved specifically in patients who 1) showed fewer OCD themes in symptomatology, 2) showed a higher level of somatoform dissociation, 3) had poor insight, and 4) had a higher initial level of overall severity of the disorder. Remission of the disorder was more likely in patients who had 1) good insight, 2) a lower initial level of anxiety, and 3) no comorbid depressive disorder.

Keywords: obsessive-compulsive disorder, treatment, cognitive behavioral therapy, treatment resistance, treatment efficacy, predictors

\section{Introduction}

Obsessive-compulsive disorder (OCD) leads to excessive distress and suffering for the patients and their families. ${ }^{1,2}$ The life of the patient is significantly restricted; patients are more likely to divorce, have no sexual experiences, and be socially isolated. The most common comorbidity is depression, which occurs in up to $55 \%$ of OCD patients. ${ }^{3,4}$ However, other common comorbidities are alcohol abuse or anxiety, as well as eating and personality disorders. ${ }^{5-7}$ Drugs that are effective in treating OCD include the selective serotonin reuptake inhibitors (SSRIs) clomipramine, mirtazapine, and venlafaxine. ${ }^{8}$ Antidepressants lead to improvement in $\sim 65 \%-70 \%$ of patients. ${ }^{9}$ Apparent treatment effect can be observed after 2-3 months of using the highest tolerated dose of antidepressants. Many authors even recommend supramaximal doses of SSRIs in treatment-resistant patients (often twice the recommended maximum dose). ${ }^{1}$ 
Among psychotherapies, cognitive behavioral therapy (CBT) is the treatment of choice. ${ }^{10,11}$ However, $~ 50 \%$ of patients do not respond optimally to purely behavioral approaches, even in combination with pharmacotherapy. One factor associated with resistance to treatment is that patients do not fully participate in exposure with response prevention because of their beliefs that the prevention of rituals leads to tragedy. Insufficient insight and severe depression have been shown to be potential problems in the treatment using exposure with response prevention. ${ }^{12-16}$ However, according to some studies, a lack of insight may not always be a predictor of poor therapeutic response. ${ }^{12,17} \mathrm{~A}$ higher degree of dissociation may prevent the effect of $\mathrm{CBT}^{16,18-20}$ and psychodynamic psychotherapy. ${ }^{21}$

In routine clinical practice, medication and $\mathrm{CBT}$ are often combined. ${ }^{22}$ However, this approach does not lead to greater efficacy than CBT alone, as shown by numerous studies. ${ }^{11,23-27}$ However, the higher effect of the combination was seen in a recent meta-analysis, which calculated the amount of effect (effect size) in both studies that compared medication with behavioral therapy and separate studies without direct comparison. ${ }^{28}$ In pharmacotherapy, treatment discontinuation is often followed by a relapse. If medication is combined with CBT, patients are protected against relapse even if they discontinue the drugs. ${ }^{29}$

The characteristics associated with resistance to treatment include comorbidities, particularly depression and personality disorders. Some studies also examined the relationship between dissociation and the therapeutic effect and suggested that the higher degree of dissociation led to decreased therapeutic efficacy. ${ }^{16,20}$ Therapeutic response is also diminished by marked cognitive impairment. ${ }^{30} \mathrm{~A}$ better prognosis is usually associated with higher socioeconomic status, an episodic course of the disorder, and the presence of a precipitating stressful event. ${ }^{31}$ Mataix-Cols et al ${ }^{132}$ used a factor analysis of the Yale-Brown Obsessive Compulsive Scale (Y-BOCS) in 354 patients and concluded that only 5\% of factors explained $65.5 \%$ of the variance in the results. The symptoms related to symmetry and order, contamination and washing, aggression, and sexual and religious obsessions mainly contributed to the final score. The most common predictors of poor therapeutic outcome are higher frequency and intensity of symptoms, the presence of contamination and hoarding rituals, ${ }^{33}$ a positive family history, personality disorders, body dysmorphic disorder, a late onset of the disorder, longer duration and chronicity, more psychiatric hospitalizations, and comorbid tic disorder. ${ }^{34}$ Ravizza et al ${ }^{35}$ tried to identify the predictors of successful treatment in 53 patients taking clomipramine or fluoxetine for 6 months.
Therapeutic response, defined as a $40 \%$ reduction in the Y-BOCS score, was achieved in $58.5 \%$ of patients. Patients who did not respond adequately showed a higher frequency of urge washing rituals, chronic course and longer duration of the disease, young age at disease onset, and comorbid schizotypal disorder. Alonso et $\mathrm{al}^{36}$ attempted to predict long-term results in combined treatment with SSRIs and behavioral therapies. Of all the Y-BOCS items, poor treatment outcome was associated with sexual obsessions and religious contents.

Hantouche et $\mathrm{al}^{37}$ conducted a 1 -year naturalistic study in 155 patients with OCD. The main predictors of insufficient therapeutic response to both SSRIs and behavioral therapy were little insight and obsessional slowness, while higher levels of impulsivity predicted a better response. In a 2-year study of 122 patients with OCD taking SSRIs, Shetti et al ${ }^{38}$ found that the lack of therapeutic response was related to comorbid depressive disorders, poor insight, the presence of sexual obsessions, washing, and multiple obsessions. It seems that the predictors of treatment response have only rarely been confirmed in other studies. Saxena et $\mathrm{l}^{39}$ found that patients with hoarding rituals responded to treatment with paroxetine as well as those with other types of rituals. In another study, the presence of body dysmorphic disorder impaired therapeutic response. Steketee et al investigated whether the therapeutic effect of venlafaxine or paroxetine was linked to a genetic predisposition. ${ }^{14}$ It was shown that the efficacy of venlafaxine and paroxetine was associated with the S/L genotype of the polymorphism of the serotonin transporter 5-HTTLPR and the G/G genotype of the 5-HT2A polymorphism, respectively. ${ }^{40}$

The aim of the present study was to determine whether the condition of patients with OCD resistant to drug therapy could be improved by intensive and systematic CBT lasting for 6 weeks and whether it was possible to predict the therapeutic effect using demographic, clinical, and selected psychological characteristics at baseline.

\section{Methods}

\section{Patients}

Two psychiatrists independently carried out the evaluation. The diagnosis of OCD was made according to the International Classification of the Diseases, 10th edition ${ }^{41}$ criteria for research and confirmed by a psychologist using the structured Mini International Neuropsychiatric Interview. ${ }^{42}$ For the inclusion of the study, the patients were 1) in the age group 18-65 years and 2) with Y-BOCS higher than 16 , and 3) there were, at least, two unsuccessful treatment attempts using treatment guidelines before index treatment. 
The exclusion criteria were 1) severe depression (Beck Depression Inventory [BDI] score $>50$ ), 2) high suicidal risk, 3) lifetime comorbid psychotic disorder, 4) lifetime comorbid bipolar disorder, 5) addiction, 6) organic mental disorder, 7) eating disorder, 8) serious physical illness, 9) epilepsy, 10) noncompliant patient, and 11) antisocial personality disorder. The trial registration for this study is research grant IGA MZ CR NS 9752-3/2008.

\section{Measurements}

Mini International Neuropsychiatric Interview ${ }^{42}$ is a diagnostic tool and was used for basic screening for mental disorders meeting the Axis I criteria according to the Diagnostic and Statistical Manual of Mental Disorders - 4th edition and International Classification of the Diseases, 10th edition. $^{43,44}$

$\mathrm{Y}-\mathrm{BOCS}^{45,46}$ is a rating scale and was used to assess the severity of OCD. Objective Y-BOCS (Y-BOCSobj) and subjective Y-BOCS (S-Y-BOCS) filled out by a professional rater and the patients, respectively, were used. Previous studies showed that correlation between the Czech versions of S-Y-BOCS and Y-BOCSobj was high. ${ }^{16,47}$

Clinical Global Impression $(\mathrm{CGI})^{48}$ is another rating scale that was used for measuring the overall severity of the disorder. Both the objective (CGIobj) and subjective (S-CGI) versions evaluated the overall severity on a 1-7 scale, with characteristics being described for each degree of severity. CGI has good reliability, as assessed using a measure of agreement between independent raters and the evaluation of the physician and the patient. ${ }^{49}$

For evaluating the effect of treatment, several major indicators were used:

- The relative change in S-Y-BOCS is the ratio between the absolute change and the first assessment of the S-YBOCS total score.

- The relative change in CGIobj indicates the ratio between the absolute change and the first evaluation of CGIobj.

Clinical improvement was assessed using the following major criteria:

- Improvements in the treatment were characterized by a decrease in S-Y-BOCS by $>35 \%$.

- The achievement of clinical remission was characterized by CGIobj final scores of 1 or 2 .

Beck Anxiety Inventory (BAI) $)^{50-53}$ is a self-rating tool for evaluating the most common symptoms of anxiety. BAI was shown to have moderate to high convergent validity with other questionnaires and scales of anxiety $(P>0.5)$; the internal consistency (Cronbach's $\alpha$ ) of the BAI questionnaire is $0.93 .^{53}$ The advantage of the inventory is its sensitivity to changes in anxiety symptoms achieved during psychotherapeutic or pharmacological treatments. ${ }^{54}$

$\mathrm{BDI}^{55}$ is a well-known self-rating questionnaire for measuring depression. Like BAI, BDI can respond sensitively to the change in status during treatment. ${ }^{56}$ Conversion and standardization to the Czech environment were carried out by Preiss and Vacír. ${ }^{57}$

Dissociative Experiences Scale (DES) ${ }^{58}$ is a subjective 28 -item visual analog scale with values 0-100, which evaluates the nonpathological and pathological forms of dissociation. The Czech version of DES showed internal consistency (Cronbach's $\alpha$ ) of 0.92 , and the test-retest reliability after 6-8 weeks was sufficient $(r=0.84, P<0.001) .{ }^{59}$

20-Item Somatoform Dissociation Questionnaire (SDQ-20) ${ }^{60}$ is a questionnaire showing physical symptoms associated with the process of dissociation. The questionnaire is highly correlated with DES. ${ }^{61}$ In a study of OCD patients, it was highly correlated with DES and BAI, with treatmentresistant patients showing higher scores. ${ }^{16}$

Sheehan Disability Scale (SDS) ${ }^{62}$ is a visual analog scale for assessing subjectively perceived disabilities. The instrument is often used to evaluate disabilities in anxiety disorders, ${ }^{63-65}$ including OCD. ${ }^{66}$ Its three items are complemented by a fourth dimension to which the patient records the levels of stress in the same visual analog scale as above three items. ${ }^{67}$

The schedule for using the tools is given in Table 1.

\section{Treatment}

All patients were treated in an outpatient psychotherapeutic program for 6 weeks. The program consisted of 30 group sessions and six individual sessions of CBT in combination

Table I Time schedule for using the tools

\begin{tabular}{llll}
\hline Tool & $\begin{array}{l}\text { Beginning of } \\
\text { the treatment }\end{array}$ & Weeks I-5 & $\begin{array}{l}\text { End of the } \\
\text { treatment }\end{array}$ \\
\hline ICD-10 & $\times$ & & \\
MINI & $\times$ & $\times$ \\
CGlobj & $\times$ & & \\
S-CGI & $\times$ & $\times$ & \\
Y-BOCSobj & $\times$ & & \\
S-Y-BOCS & $\times$ & $\times$ \\
SDS & $\times$ & $\times$ & \\
BAI & $\times$ & $\times$ & \\
BDI & $\times$ & & \\
DES & $\times$ & & \\
SDQ-20 & $\times$ & & \\
\hline
\end{tabular}

Abbreviations: BAI, Beck Anxiety Inventory; BDI, Beck Depression Inventory; CGlobj, objective Clinical Global Impression; DES, Dissociative Experiences Scale; ICD- I0, International Classification of Diseases, tenth revision; MINI, Mini International Neuropsychiatric Interview; S-CGI, subjective Clinical Global Impression; SDS, Sheehan Disability Scale; SDQ-20, 20-item Somatoform Dissociation Questionnaire; S-Y-BOCS, subjective Yale-Brown Obsessive Compulsive Scale; Y-BOCSobj, objective Yale-Brown Obsessive Compulsive Scale. 
with pharmacotherapy. Apart from the group and individual sessions, the program included additional supporting activities, such as progressive muscle relaxation, communication training, and sports activities. The patients were treated with their usual doses of previously administered medication for OCD. Only minimal changes were made to the doses.

\section{Statistics and ethics}

The data were processed by the statistical software SPSS (Version 21.0; IBM Corporation, Armonk, NY, USA) and Prism (Version 5.0; GraphPad Software, Inc., La Jolla, CA, USA). The study was approved by the Common Ethics Committee of the Prague Psychiatric Centre and Prague Psychiatric Hospital and carried out according to the latest version of the Declaration of Helsinki and the principles of good practice. Before enrolling in the study, all participants gave signed informed consent.

\section{Results}

\section{Patients}

There were 66 patients included in the study. Fifty-seven patients completed the study. There were nine dropouts; of those, five did not collaborate and failed to fill in the questionnaires, and four discontinued their treatment prematurely. The reasons for premature discontinuation varied, with two patients interrupting their treatment because of family problems, and the other two not accepting exposure therapy. The mean age of patients who completed the study was $\sim 32$ years. There were slightly more women $(57.9 \%)$ in the study (Table 2). On average, anxiety was of moderate severity, as determined by BAI, and depression was mild-tomoderate severity, as self-assessed using BDI.

The SDS scores indicated that, on average, the patients' work or school work, family life, and social life were moderately disrupted. The degree of distress experienced by patients was also moderate, on average. The daily doses of antidepressants corresponded to a higher dosage, very typically used in patients with OCD. ${ }^{68}$

Age was significantly positively correlated with the degree of somatoform dissociation measured by SDQ (Spearman's $r=0.31 ; P<0.05$ ). This relationship was not found in psychological dissociation rated using DES (Pearson's $r=0.1796$, nonsignificant).

The comparison of the sexes showed significantly higher Y-BOCSobj compulsion and total scores as well as S-Y-BOCS obsession and total scores in women. They also had significantly higher anxiety and depression scores measured by BAI and BDI but not scores of psychological or somatoform dissociation (Table 3). The frequency of comorbid disorders, whether depressive, anxiety, or personality, was balanced between the sexes.

The age of disease onset was statistically significantly correlated with the severity of compulsions as measured by Y-BOCSobj and the severity of the disorder as measured by CGIobj (Table 4).

\section{Treatment results}

There were statistically significant improvements in the mean scores of all rating scales in the course of treatment (Table 5). The relative changes in the mean S-Y-BOCS and CGIobj scores were $0.39 \pm 0.24$ and $0.35 \pm 0.21$, respectively. Clinical improvement, ie, a decrease of $35 \%$ or more in S-Y-BOCS, occurred in 37 patients $(64.9 \%)$. Clinical remission (CGIobj scores 1 or 2 ) was achieved by 28 patients (49.1\%).

During the treatment, there was a statistically significant decrease in the S-Y-BOCS total score (Table 5). Statistical evaluation using Tukey's multiple comparison tests showed significant differences starting from week 3 of treatment.

This decrease was equally contributed by the decreased mean S-Y-BOCS scores for obsessions and compulsions (Table 5). Similar results were found using BAI, with Tukey's multiple comparison tests showing a statistically significant decline after week 4. It seems that general nonspecific anxiety decreased slightly later than specific obsessions and compulsions. During the treatment, there was also a significant reduction in depressive symptomatology, as measured by BDI (Table 5). Turkey's multiple comparison tests showed that the decline in BDI scores started to be statistically significant in week 3 of treatment, similar to S-Y-BOCS.

\section{Treatment efficacy and demographic and clinical factors}

There was no correlation between the age, duration of the disorder, declared age of disease onset, and treatment efficacy (Table 6). The severity of anxiety assessed at baseline using BAI was not correlated with relative changes in the main outcome criteria during the treatment. Additionally, the severity of depression at baseline was not correlated with relative changes in S-Y-BOCS or CGIobj (Table 6). There was also no correlation between Y-BOCSobj, S-Y-BOCS, SDS home, SDS family, and SDS total scores at baseline and changes in the main outcome criteria. However, there were statistically significant positive correlations between $\mathrm{S}-\mathrm{CGI}$ at baseline and the S-Y-BOCS relative change as well as between SDS-work/school and the CGIobj relative change (Table 6). 
Table 2 Demographic and clinical data at the beginning of the treatment

\begin{tabular}{|c|c|}
\hline Age (years) & $31.74 \pm 8.82$ \\
\hline Sex & 24 males and 33 females \\
\hline Years of education & $14.1 \mid \pm 3.03$ \\
\hline Age of disease onset (years) & $15.25 \pm 6.98$ \\
\hline Duration of the disorder (years) & $|6.23 \pm 9.4|$ \\
\hline Beginning of the treatment (years) & $24.77 \pm 7.61$ \\
\hline Treatment delay (years) & $9.53 \pm 6.92$ \\
\hline \multicolumn{2}{|l|}{ Y-BOCSobj } \\
\hline Total score & $24.30 \pm 6.16$ \\
\hline Obsessions & $11.63 \pm 3.04$ \\
\hline Compulsions & $13.06 \pm 4.37$ \\
\hline \multicolumn{2}{|l|}{ S-Y-BOCS } \\
\hline Total score & $24.46 \pm 6.98$ \\
\hline Obsessions & $12.37 \pm 3.72$ \\
\hline Compulsions & $12.46 \pm 4.29$ \\
\hline \multicolumn{2}{|l|}{ SDS } \\
\hline Total score & $14.85 \pm 7.20$ \\
\hline Work/school & $4.66 \pm 2.90$ \\
\hline Family life & $5.25 \pm 2.6 \mathrm{I}$ \\
\hline Social life & $4.92 \pm 2.79$ \\
\hline Distress level & $5.86 \pm 2.50$ \\
\hline SDQ-20 & $26.26 \pm 7.11$ \\
\hline DES & $18.55 \pm 18.65$ \\
\hline CGlobj & $4.12 \pm 1.14$ \\
\hline S-CGI & $4.53 \pm 0.78$ \\
\hline BAI & $22.04 \pm 13.00$ \\
\hline BDI & $18.43 \pm 11.43$ \\
\hline Antidepressant dosage (equivalent of paroxetine) & $45.06 \pm 26.72$ \\
\hline \multicolumn{2}{|l|}{ Additional medication (number of patients) } \\
\hline Antipsychotics & $\begin{array}{l}16(28.1 \%) \text {; ziprasidone } 2 \times \text {, risperidone } 4 \times \text {, olanzapine } 4 \times \text {, melperone } I \times \text {, chlorprothixene } 2 \times \text {, } \\
\text { haloperidol IX, quetiapine IX, and aripiprazole IX }\end{array}$ \\
\hline Anticonvulsants & $3(5.3 \%) ;$ lamotrigine $2 \times$ and valproate $I \times$ \\
\hline Anxiolytics & 2 (3.5\%); diazepam IX and bromazepam IX \\
\hline Without medication & $7(12.3 \%)$ \\
\hline Comorbidity with another axis I disorder & $32(56.1 \%)$ \\
\hline Comorbid diagnosis & $\begin{array}{l}\text { Social phobia } 6 \times \text {, generalized anxiety disorder II } \times \text {, panic disorder } 2 \times \text {, post-traumatic stress } \\
\text { disorder IX, dysthymia } 8 \times \text {, depressive disorder } 9 \times\end{array}$ \\
\hline More than one comorbid disorder & 4 \\
\hline Comorbidity with personality disorder & $31(54.4 \%)$ \\
\hline Personality disorder & $\begin{array}{l}\text { Borderline IIX, narcissistic } 6 \times \text {, dependent } 3 \times \text {, obsessive-compulsive } 5 \times \text {, avoidant } I \times \text {, schizoid } \\
2 \times \text {, and histrionic } 3 \times\end{array}$ \\
\hline
\end{tabular}

Note: Data presented as mean \pm SD.

Abbreviations: CGlobj, objective Clinical Global Impression; BAI, Beck Anxiety Inventory; BDI, Beck Depression Inventory; DES, Dissociative Experiences Scale; S-CGI, subjective Clinical Global Impression; SD, standard deviation; SDS, Sheehan Disability Scale; SDQ-20, 20-item Somatoform Dissociation Questionnaire; S-Y-BOCS, subjective Yale-Brown Obsessive Compulsive Scale; Y-BOCSobj, objective Yale-Brown Obsessive Compulsive Scale.

There was no difference between unemployed and employed patients in any outcome criteria of treatment efficacy (Table 7).

Obsessions and compulsions associated with an enormous need to check were most prevalent in the study group, followed by fear of contamination and excessive washing, magical and aggressive obsessions (Table 8). Other types of obsessions occurred less frequently. The comparison according to the treatment response showed no differences among the subgroups with different kinds of obsessions and compulsions (Table 8).

Most of the patients had more than one type of obsessions and compulsions. Only 12 (21.1\%) had one type, 14 (24.63\%) had two types, 12 (21.1\%) had three types, and 19 (33.3\%) had more than three types of obsessions and compulsions. Statistical comparison of the ratios of treatment responders and nonresponders showed that patients with more types of obsessions and compulsions achieved clinical improvement 
Table 3 Comparison between the sexes in demographic and clinical data

\begin{tabular}{|c|c|c|c|}
\hline & Males $(n=24)$ & Females $(n=33)$ & Statistics \\
\hline Age (years) & $34.67 \pm 10.47$ & $29.6 I \pm 6.8 I$ & Unpaired $t$-test: $t=2.212, d f=55 ; P<0.05$ \\
\hline Age of disease onset (years) & $|5.7| \pm 7.09$ & $|4.9| \pm 6.98$ & Unpaired $t$-test: $t=0.4240, d f=55 ; \mathrm{ns}$ \\
\hline Duration of the disorder (years) & $18.75 \pm 10.28$ & $|4.39 \pm 8.4|$ & Unpaired $t$-test: $t=1.758, d f=55 ;$ ns $(P=0.08)$ \\
\hline Beginning of the treatment & $27.00 \pm 10.35$ & $24.18 \pm 6.62$ & Unpaired $t$-test: $t=0.4240, d f=55 ; \mathrm{ns}$ \\
\hline Treatment delay & $11.58 \pm 8.84$ & $8.03 \pm 4.17$ & Unpaired $t$-test: $t=1.962, d f=55 ; \mathrm{ns}(P=0.055)$ \\
\hline Years of education & $14.42 \pm 3.79$ & $13.89 \pm 2.37$ & Mann-Whitney $U$-test: $U=3 \mid 5 ;$ ns \\
\hline \multicolumn{4}{|l|}{ Y-BOCSobj } \\
\hline Obsessions & $10.79 \pm 2.23$ & $12.24 \pm 3.42$ & Unpaired $t$-test: $t=|.8| 5, d f=55 ;$ ns $(P=0.075)$ \\
\hline Compulsions & $\mid 1.71 \pm 3.78$ & $14.03 \pm 4.57$ & Unpaired $t$-test: $t=2.034, d f=55 ; P<0.05$ \\
\hline Total score & $22.00 \pm 4.75$ & $25.97 \pm 6.58$ & Unpaired $t$-test: $t=2.5 \mid 4, d f=55 ; P<0.05$ \\
\hline CGlobj & $3.88 \pm 1.04$ & $4.30 \pm 1.19$ & Mann-Whitney $U$-test: $U=305.5 ;$ ns \\
\hline S-Y-BOCS obsessions & $11.13 \pm 2.77$ & $13.27 \pm 4.08$ & Unpaired $t$-test: $t=2.230, d f=55 ; P<0.05$ \\
\hline S-Y-BOCS compulsions & $11.83 \pm 3.83$ & $|2.9| \pm 4.60 \mid$ & Unpaired $t$-test: $t=0.9339, d f=55 ; \mathrm{ns}$ \\
\hline S-Y-BOCS total score & $22.50 \pm 4.63$ & $25.88 \pm 7.42$ & Unpaired $t$-test: $t=1.843, d f=55 ; n s(P=0.07)$ \\
\hline BAI & $17.50 \pm 10.10$ & $25.33 \pm 14.00$ & Unpaired $t$-test: $t=2.333, d f=55 ; P<0.05$ \\
\hline BDI & $|5.25 \pm 7.6|$ & $21.39 \pm 13.06$ & Unpaired $t$-test: $t=2.06 \mathrm{I}, d f=55 ; P<0.05$ \\
\hline SDQ-20 & $26.29 \pm 6.96$ & $26.24 \pm 7.32$ & Mann-Whitney U-test: $U=383 ;$ ns \\
\hline DES & $17.97 \pm 21.98$ & $18.97 \pm 16.15$ & Mann-Whitney $U$-test: $U=347$; ns \\
\hline Comorbidity with depressive disorder & $4: 20$ & $5: 28$ & Fisher's exact test; ns \\
\hline Comorbidity with another axis I disorder & $7: 17$ & $12: 21$ & Fisher's exact test; ns \\
\hline Comorbidity with personality disorder & $14: 10$ & $17: 16$ & Fisher's exact test; ns \\
\hline
\end{tabular}

Note: Data presented as mean \pm SD or as a ratio.

Abbreviations: BAI, Beck Anxiety Inventory; BDI, Beck Depression Inventory; CGlobj, objective Clinical Global Impression; DES, Dissociative Experiences Scale; ns, nonsignificant; SD, standard deviation; SDQ-20, 20-item Somatoform Dissociation Questionnaire; S-Y-BOCS, subjective Yale-Brown Obsessive Compulsive Scale; Y-BOCSobj, objective Yale-Brown Obsessive Compulsive Scale.

Table 4 Correlation of the age of disease onset and scores in the assessment questionnaires

\begin{tabular}{|c|c|c|c|c|c|c|c|c|c|c|c|}
\hline Measurement & Y-BOCS & $\begin{array}{l}\text { Y-BOCSobj } \\
\text { obsessions }\end{array}$ & $\begin{array}{l}\text { Y-BOCSobj } \\
\text { compulsions }\end{array}$ & $\begin{array}{l}\text { Insight } \\
\text { into } \\
\text { obsessions }\end{array}$ & $\begin{array}{l}\text { Resistance } \\
\text { to } \\
\text { obsessions }\end{array}$ & CGI & $\begin{array}{l}\text { S-Y- } \\
\text { BOCS }\end{array}$ & $\begin{array}{l}\text { S-Y-BOCS } \\
\text { obsessions }\end{array}$ & $\begin{array}{l}\text { S-Y-BOCS } \\
\text { compulsions }\end{array}$ & BAI & BDI \\
\hline $\begin{array}{l}\text { Pearson's or } \\
\text { Spearman's } r\end{array}$ & $-0.240^{P}$ & $-0.188^{P}$ & $-0.324^{\mathrm{P}}$ & $-0.098^{\mathrm{s}}$ & $0.029^{s}$ & $-0.431^{s}$ & $-0.278^{P}$ & $-0.121^{P}$ & $-0.23 I^{P}$ & $0.079^{P}$ & $0.31 I^{P}$ \\
\hline$P$-value & ns $(P=0.07)$ & ns & $P<0.05$ & ns & ns & $P<0.001$ & ns & ns & ns $(P=0.09)$ & ns & ns \\
\hline
\end{tabular}

Notes: PPearson's r. SSpearman's $r$.

Abbreviations: BAI, Beck Anxiety Inventory; BDI, Beck Depression Inventory; CGI, Clinical Global Impression; ns, nonsignificant; S-Y-BOCS, subjective Yale-Brown Obsessive Compulsive Scale; Y-BOCS, Yale-Brown Obsessive Compulsive Scale; Y-BOCSobj, objective Yale-Brown Obsessive Compulsive Scale.

Table 5 Mean scores on rating scales during the treatment

\begin{tabular}{|c|c|c|c|c|c|c|c|}
\hline Measurement & Week 0 & Week I & Week 2 & Week 3 & Week 4 & Week 5 & Week 6 \\
\hline Number & 57 & 53 & 55 & 57 & 56 & 55 & 54 \\
\hline S-Y-BOCS total score & $24.46 \pm 6.98$ & $23.17 \pm 7.00$ & $21.79 \pm 7.84$ & $19.86 \pm 7.99$ & $18.07 \pm 7.73$ & $16.36 \pm 6.56$ & $15.19 \pm 6.43$ \\
\hline Statistics & \multicolumn{7}{|c|}{ One-way ANOVA: $F=12.82, d f=387 ; P<0.000 I$; Tukey's multiple comparison tests: significant differences from week 3} \\
\hline S-Y-BOCS obsessions & $12.37 \pm 3.72$ & $11.72 \pm 3.92$ & $11.15 \pm 4.08$ & $10.09 \pm 3.97$ & $9.38 \pm 4.18$ & $8.66 \pm 3.47$ & $8.06 \pm 3.15$ \\
\hline Statistics & \multicolumn{7}{|c|}{ One-way ANOVA: $F=9.887, d f=387 ; P<0.000 I$; Tukey's multiple comparison tests: significant differences from week 3} \\
\hline S-Y-BOCS compulsions & $12.46 \pm 4.29$ & $11.45 \pm 3.86$ & $10.65 \pm 4.58$ & $9.84 \pm 4.48$ & $8.63 \pm 4.30$ & $7.91 \pm 3.69$ & $7.26 \pm 3.55$ \\
\hline Statistics & \multicolumn{7}{|c|}{ One-way ANOVA: $F=I I .82, d f=387 ; P<0.000 I$; Tukey's multiple comparison tests: significant differences from week 3} \\
\hline Number & 57 & 57 & 57 & 57 & 57 & 55 & 53 \\
\hline BAI & $22.04 \pm 13.00$ & $19.70 \pm 1 \mid .81$ & $17.35 \pm 10.43$ & $16.30 \pm 9.59$ & $15.58 \pm 10.64$ & $15.35 \pm 10.35$ & $12.68 \pm 7.96$ \\
\hline Statistics & \multicolumn{7}{|c|}{ One-way ANOVA: $F=4.613, d f=392 ; P<0.0005$; Tukey's multiple comparison tests: significant differences from week 4} \\
\hline Number & 57 & 57 & 57 & 56 & 57 & 55 & 57 \\
\hline BDI & $|8.81 \pm 1| .43$ & $16.26 \pm 10.29$ & $|4.8| \pm 9.80$ & $|3.1| \pm 9.23$ & $14.26 \pm 9.88$ & $12.76 \pm 8.87$ & $11.11 \pm 7.49$ \\
\hline Statistics & \multicolumn{7}{|c|}{ One-way ANOVA: $F=3.898, d f=395 ; P<0.001$; Tukey's multiple comparison tests: significant differences from week 3} \\
\hline
\end{tabular}

Note: Data presented as mean \pm SD.

Abbreviations: ANOVA, analysis of variance; BAI, Beck Anxiety Inventory; BDI, Beck Depression Inventory; SD, standard deviation; S-Y-BOCS, subjective Yale-Brown Obsessive Compulsive Scale. 
Table 6 Correlations between the disease onset and treatment efficacy

\begin{tabular}{lll}
\hline Independent factor & \multicolumn{2}{l}{ Indicator of the change } \\
\cline { 2 - 3 } & $\begin{array}{l}\text { S-Y-BOCS } \\
\text { relative change }\end{array}$ & $\begin{array}{l}\text { CGlobj } \\
\text { relative change }\end{array}$ \\
\hline Age & $-0.118^{\mathrm{P}}$ & $0.125^{\mathrm{P}}$ \\
Duration of the disorder & $0.169^{\mathrm{P}}$ & $0.138^{\mathrm{P}}$ \\
Age of disease onset & $-0.118^{\mathrm{P}}$ & $0.125^{\mathrm{P}}$ \\
Y-BOCSobj-0 & $0.1154^{\mathrm{P}}$ & $0.0173^{\mathrm{S}}$ \\
S-Y-BOCS - & $0.0981^{\mathrm{P}}$ & $0.1253^{\mathrm{P}}$ \\
CGlobj - & $0.0794^{\mathrm{S}}$ & $-0.3309^{\mathrm{S}, *}$ \\
BAI - 0 & $-0.0223^{\mathrm{P}}$ & $0.1231^{\mathrm{P}}$ \\
BDI - 0 & $-0.1919^{\mathrm{P}}$ & $0.1338^{\mathrm{P}}$ \\
S-CGI - 0 & $0.4005^{\mathrm{S}, * *}$ & $0.0595^{\mathrm{S}}$ \\
SDS work/school & $0.1764^{\mathrm{P}}$ & $-0.2946^{\mathrm{P}, *}$ \\
SDS home & $0.1016^{\mathrm{P}}$ & $-0.1234^{\mathrm{P}}$ \\
SDS family & $0.2342^{\mathrm{P}}$ & $-0.0029^{\mathrm{P}}$ \\
SDS total score & $0.199^{\mathrm{P}}$ & $-0.1631^{\mathrm{P}}$ \\
\hline Notes: &
\end{tabular}

Notes: PPearson's $r$. SSpearman's $r$. $* P<0.05 ; * * P<0.01$. The 0 refers to time zero ie, before the start of treatment.

Abbreviations: BAI, Beck Anxiety Inventory; BDI, Beck Depression Inventory; CGlobj, objective Clinical Global Impression; S-CGI, subjective Clinical Global Impression; SDS, Sheehan Disability Scale; S-Y-BOCS, subjective Yale-Brown Obsessive Compulsive Scale; Y-BOCSobj, objective Yale-Brown Obsessive Compulsive Scale.

significantly more frequently (chi-square: $d f=12.40,3$; $P<0.01)$.

Changes in OCD symptomatology measured using relative changes in S-Y-BOCS, and CGIobj did not correlate with the degree of dissociation (Table 9).

The severity of somatoform dissociation measured with SDQ-20 was positively correlated with a relative change in the treatment outcome criteria at the $5 \%$ level of statistical significance for S-Y-BOCS assessing the severity of obsessions and compulsions (Table 9).

Insight is rated on a 1-4 scale in Y-BOCSobj. The lowest value is an excellent insight into obsessions, and 4 means a firm conviction that the obsessions and compulsions are necessary to avoid tragedy (a lack of insight). Insight was statistically significantly correlated with a relative decline in S-Y-BOCS scores but not with CGIobj change (Table 9).
Seventeen patients $(29.8 \%)$ were diagnosed with comorbid depressive disorder. The mean relative change in S-Y-BOCS in patients with comorbid depression was not statistically significantly different from the average relative change in patients without depressive disorders (Table 10). Similarly, there was no statistically significant difference in CGIobj relative change between the groups. When comparing the proportions of patients who improved clinically, there was no statistically significant difference between the groups with and without depression. However, there was a statistically significant difference in the number of patients who achieved remission at the end of the treatment between the two groups (Fisher's exact test: $P<0.05$ ), with remission being noted in $60 \%$ of patients without comorbid depression and only $30.8 \%$ of cases with comorbid depression.

Thirty-one patients (54.4\%) included in the study were diagnosed with personality disorder. The most common comorbid personality disorder was borderline personality disorder (eleven patients). The other types were narcissistic (six patients), obsessive-compulsive (five patients), histrionic (three patients), dependent (three patients), schizoid (two patients), and avoidant (one patient). Improvement in the mean S-Y-BOCS scores was the same in patients with and without personality disorder. There was no statistically significant difference in treatment efficacy between these groups. The same results were found in CGIobj (Table 11). Also, the proportions of patients with an improvement of $35 \%$ or more in S-Y-BOCS and those who achieved remission did not differ between the groups with and without a comorbid personality disorder (Table 11).

\section{Multiple regression analysis of the factors affecting change during treatment}

A relative decrease in symptoms of OCD measured by $\mathrm{S}-\mathrm{Y}$-BOCS was the main indicator of improvement. The regression analysis included all variables that correlated with S-Y-BOCS in the correlation analysis (Figure 1).

Table 7 Comparison of rating scales according to the employment status

\begin{tabular}{|c|c|c|c|}
\hline & Unemployed $(n=20)$ & Employed $(n=37)$ & Statistics \\
\hline S-Y-BOCS relative change & $-0.30 \pm 0.31$ & $-0.43 \pm 0.19$ & Unpaired $t$-test: $t=1.989, d f=55 ;$ ns $(P=0.052)$ \\
\hline CGlobj relative change & $-0.34 \pm 0.23$ & $-0.36 \pm 0.21$ & Unpaired $t$-test: $t=0.2726, d f=55$; ns \\
\hline $\begin{array}{l}\text { Improvement of } 35 \% \text { or more } \\
\text { in S-Y-BOCS }\end{array}$ & $13: 7$ & $24: 13$ & Fisher's exact test: ns \\
\hline $\begin{array}{l}\text { Achieving a CGlobj score of } \\
\text { I or } 2 \text { at the end of the treatment }\end{array}$ & $9: 11$ & $24: 13$ & Fisher's exact test: ns \\
\hline
\end{tabular}

Note: Data presented as mean \pm SD or as a ratio.

Abbreviations: CGlobj, Clinical Global Impression; ns, nonsignificant; SD, standard deviation; S-Y-BOCS, subjective Yale-Brown Obsessive Compulsive Scale. 
Table 8 Responders and nonresponders and types of OCD symptomatology

\begin{tabular}{|c|c|c|c|c|c|c|c|c|c|c|}
\hline & Contamination & Checking & Aggression & Sexual & I Religious & Hoarding & Magic & Slowness & Somatic & With tics \\
\hline Responders $(n=37)$ & 24 & 17 & 9 & 5 & 4 & 3 & 13 & 7 & II & 3 \\
\hline Nonresponders $(n=20)$ & 10 & 13 & 5 & 0 & I & I & 3 & 3 & 4 & 2 \\
\hline Number & 34 & 40 & 14 & 5 & 5 & 4 & 16 & 10 & 15 & 5 \\
\hline Percentage & 59.6 & 70.2 & 24.6 & 8.8 & 8.8 & 7.0 & 28.1 & 17.5 & 26.3 & 8.8 \\
\hline Statistics & Chi-square: $d f=6.408,9 ; n s$ & & & & & & & & & \\
\hline
\end{tabular}

Abbreviations: OCD, obsessive-compulsive disorder; ns, nonsignificant.

Table 9 Correlation between dissociations, insight, and therapeutic change

\begin{tabular}{llll}
\hline Measurement & Statistics & S-Y-BOCS relative change & CGlobj relative change \\
\hline DES & Spearman's $r$ & 0.111 & 0.098 \\
& P-value & $\mathrm{ns}$ & $\mathrm{ns}$ \\
DES-T & Spearman's $r$ & 0.272 & 0.098 \\
& Statistics & $P<0.05$ & $\mathrm{~ns}$ \\
SDQ-20 & Spearman's $r$ & 0.272 & 0.098 \\
& Statistics & $P<0.05$ & $\mathrm{~ns}$ \\
Insight & Spearman's $r$ & 0.4157 & 0.06931 \\
& $P$-value & $P<0.005$ & $\mathrm{~ns}$ \\
\hline
\end{tabular}

Abbreviations: CGlobj, objective Clinical Global Impression; DES, Dissociative Experiences Scale; DES-T, Dissociative Experiences Scale-Taxon; ns, nonsignificant; SDQ-20, 20-item Somatoform Dissociation Questionnaire; S-Y-BOCS, subjective Yale-Brown Obsessive Compulsive Scale.

Table 10 Comparison of the main outcome criteria in patients with and without depression

\begin{tabular}{|c|c|c|c|}
\hline & $\begin{array}{l}\text { With comorbid depressive } \\
\text { disorder }(n=\mid 7)\end{array}$ & $\begin{array}{l}\text { Without comorbid depressive } \\
\text { disorder }(n=40)\end{array}$ & Statistics \\
\hline S-Y-BOCS relative change & $-0.43 \pm 0.11$ & $-0.37 \pm 0.28$ & Unpaired $t$-test: $t=0.9243, d f=55$; ns \\
\hline CGlobj relative change & $-0.32 \pm 0.24$ & $-0.37 \pm 0.21$ & Unpaired $t$-test: $t=0.7800, d f=55 ; \mathrm{ns}$ \\
\hline $\begin{array}{l}\text { Improvement of } 35 \% \text { or more } \\
\text { in S-Y-BOCS }\end{array}$ & $14: 3$ & $23: 17$ & Fisher's exact test: ns \\
\hline $\begin{array}{l}\text { Achieving a CGlobj score of I or } 2 \text { at } \\
\text { the end of the treatment (remission) }\end{array}$ & $4: 13$ & $24: 16$ & Fisher's exact test; $P<0.05$ \\
\hline
\end{tabular}

Note: Data presented as mean \pm SD.

Abbreviations: CGlobj, objective Clinical Global Impression; ns, nonsignificant; SD, standard deviation; S-Y-BOCS, subjective Yale-Brown Obsessive Compulsive Scale.

Table I I Comparison of treatment efficacy in patients with and without comorbid personality disorder

\begin{tabular}{|c|c|c|c|}
\hline & $\begin{array}{l}\text { Without comorbid personality } \\
\text { disorder }(n=26)\end{array}$ & $\begin{array}{l}\text { With comorbid personality } \\
\text { disorder }(n=3 I)\end{array}$ & Statistics \\
\hline S-Y-BOCS relative change & $-0.38 \pm 0.27$ & $-0.39 \pm 0.22$ & Unpaired $t$-test: $t=0.1 \mid 38, d f=55 ; n s$ \\
\hline CGlobj relative change & $-0.38 \pm 0.19$ & $-0.33 \pm 0.23$ & Unpaired $t$-test: $t=0.7867, d f=55 ; \mathrm{ns}$ \\
\hline $\begin{array}{l}\text { Improvement of } 35 \% \text { or } \\
\text { more in S-Y-BOCS }\end{array}$ & $16: 10$ & $21: 10$ & Fisher's exact test: ns \\
\hline $\begin{array}{l}\text { Achieving a CGlobj score of I or } 2 \text { at } \\
\text { the end of the treatment (remission) }\end{array}$ & $14: 12$ & $14: 17$ & Fisher's exact test: ns \\
\hline
\end{tabular}

Note: Data presented as mean \pm SD or as a ratio.

Abbreviations: CGlobj, objective Clinical Global Impression; ns, nonsignificant; S-Y-BOCS, subjective Yale-Brown Obsessive Compulsive Scale. 


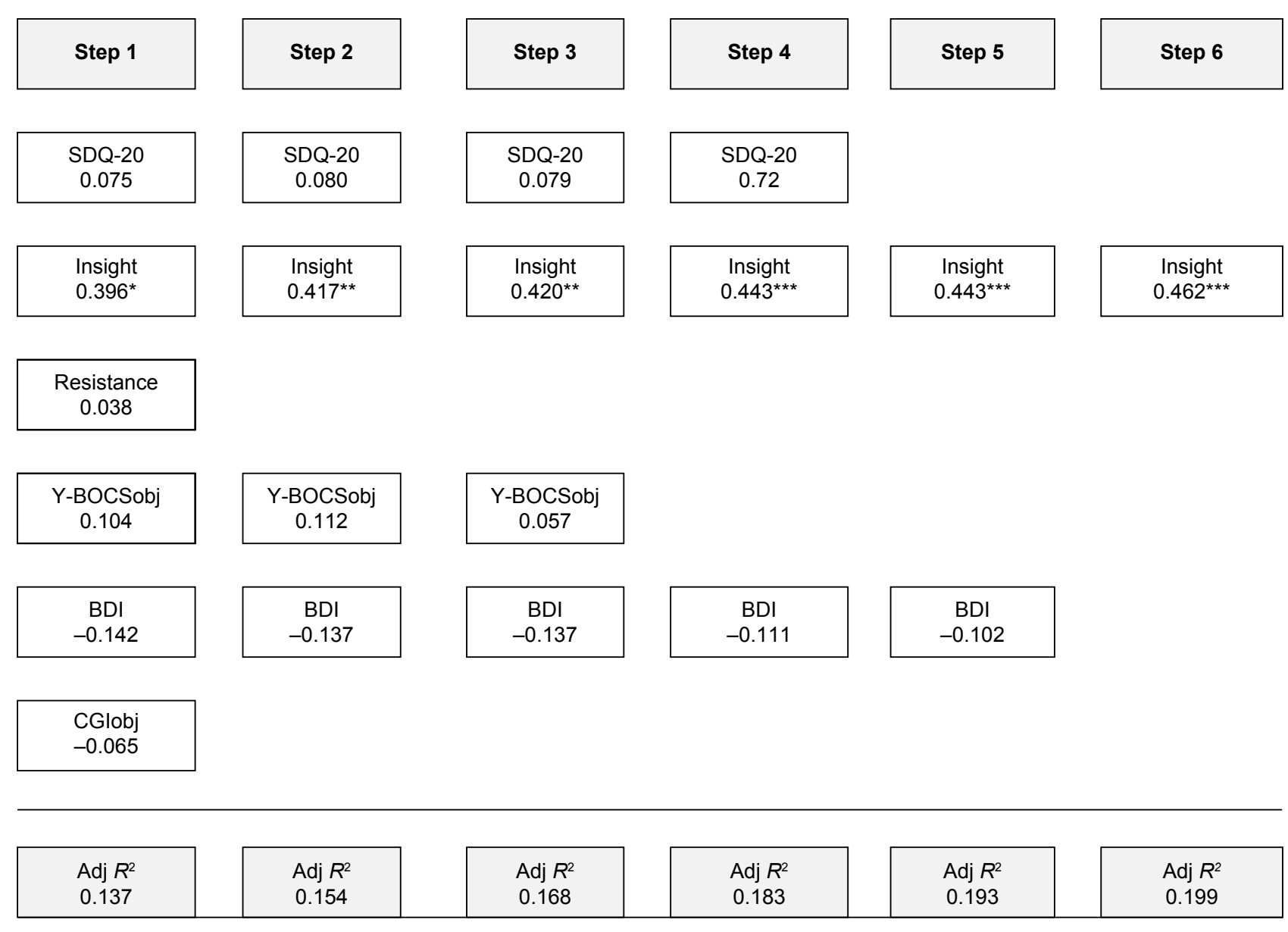

Figure I Results of stepwise regression using relative change in S-Y-BOCS as a dependent variable.

Notes: Variable, beta sign. $* P<0.05 ; * * P<0.01$; $* * * P<0.001$.

Abbreviations: Adj $R^{2}$, adjusted $R^{2}$; BDI, Beck Depression Inventory; CGlobj, objective Clinical Global Impression; S-Y-BOCS, subjective Yale-Brown Obsessive Compulsive Scale; SDQ-20, 20-item Somatoform Dissociation Questionnaire; Y-BOCSobj, objective Yale-Brown Obsessive Compulsive Scale.

The main predictor of relative change in S-Y-BOCS was baseline insight. This model explains $19.9 \%$ of the variance of the relative change in S-Y-BOCS.

A relative decrease in the severity of the disorder measured by CGIobj was the second main indicator of improvement. Figure 2 shows the steps of regression analysis, which included all variables that correlated with the change in CGIobj in the correlation analysis (Figure 3).

The stepwise regression indicated that the most statistically significant predictor of the relative change in CGIobj during treatment was the initial CGIobj. This model explains $11.2 \%$ of the variance of the relative change in CGIobj.

\section{Logistic regression analysis of remission vs failure to achieve remission}

Binary logistic regression was focused on the strength of the relationship between variables closely related to the rate of remission (a CGIobj score of 1 or 2 at the end of the treatment). The specific method used was a backward stepwise regression (Figure 2).

The final model explained $64.8 \%$ of the variance of the dependent variable. The final predictors (BAI, the number of OCD themes, CGIobj, and insight) have a high impact on the likelihood of achieving remission during combination therapy for OCD (Figure 3).

\section{Discussion}

The study sample had similar characteristics, regarding the age, years of education, duration of the disorder, and treatment delay, to other research studies evaluating the effectiveness of treatment in OCD patients, with a slight predominance of women. The mean age of the patients was $\sim 32$ years, corresponding to other clinical trials. ${ }^{16,20,69,70}$ Similarly, the average age of disease onset was $\sim 15$ years, consistent with findings of other authors. ${ }^{70,71}$ A delay of several (8-23) years from the onset of the treatment is common in OCD patients, as 


\begin{tabular}{|c|c|c|}
\hline Step 1 & Step 2 & Step 3 \\
\hline $\begin{array}{l}\text { BAl } \\
1.943\end{array}$ & $\begin{array}{c}\mathrm{BAl} \\
4.676^{*}\end{array}$ & $\begin{array}{c}\text { BAl } \\
6.524^{*}\end{array}$ \\
\hline $\begin{array}{l}\text { BDI } \\
0.128\end{array}$ & & \\
\hline $\begin{array}{l}\text { Number of OCD themes } \\
4.889^{*}\end{array}$ & $\begin{array}{c}\text { Number of OCD themes } \\
4.826^{*}\end{array}$ & $\begin{array}{l}\text { Number of OCD themes } \\
5.093^{*}\end{array}$ \\
\hline $\begin{array}{c}\text { Comorbid depression } \\
0.715\end{array}$ & $\begin{array}{c}\text { Comorbid depression } \\
2.161\end{array}$ & \\
\hline $\begin{array}{l}\text { CGlobj } \\
9.511^{* *}\end{array}$ & $\begin{array}{l}\text { CGlobj } \\
9.665^{\star *}\end{array}$ & $\begin{array}{l}\text { CGlobj } \\
10.651^{* * *}\end{array}$ \\
\hline $\begin{array}{l}\text { Insight } \\
3.587\end{array}$ & $\begin{array}{l}\text { Insight } \\
3.482\end{array}$ & $\begin{array}{l}\text { Insight } \\
3.180\end{array}$ \\
\hline $\begin{array}{c}N R^{2} \\
0.679\end{array}$ & $\begin{array}{c}N R^{2} \\
0.678\end{array}$ & $\begin{array}{c}N R^{2} \\
0.648\end{array}$ \\
\hline
\end{tabular}

Figure 2 Results of logistic regression using patients in remission versus patients who did not achieve remission as a dependent variable. Notes: Variable, wald sign. $N R^{2}$, Nagelkerke $R^{2}$. $* \mathrm{P}<0.05$; $* * \mathrm{P}<0.0 \mathrm{I}$; $* * * \mathrm{P}<0.00 \mathrm{I}$.

Abbreviations: BAI, Beck Anxiety Inventory; CGlobj, objective Clinical Global Impression; OCD, obsessive-compulsive disorder.

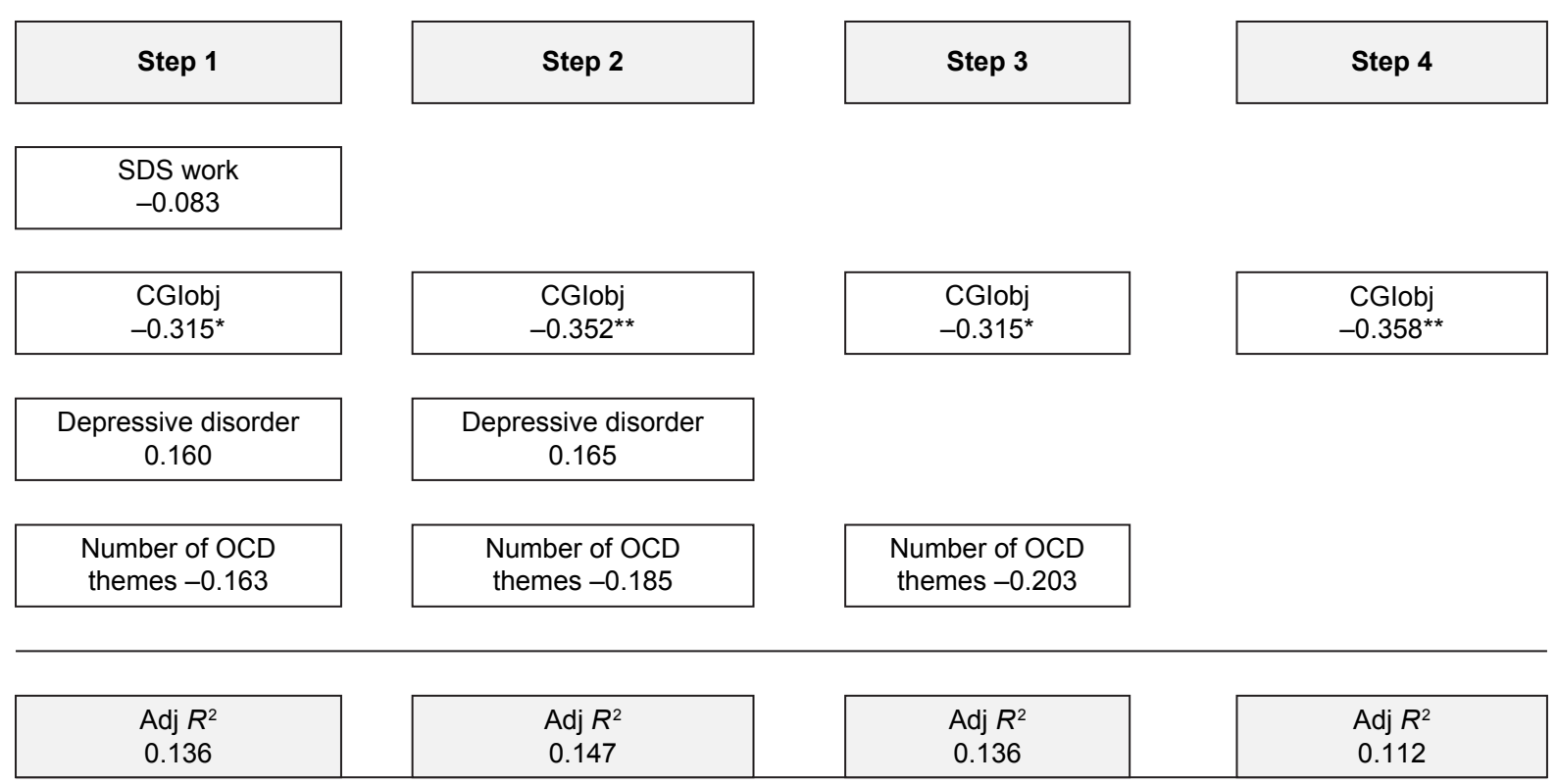

Figure 3 Results of stepwise regression using relative change in CGlobj as a dependent variable.

Notes: Variable, beta sign. $* P<0.05 ; * * P<0.01$.

Abbreviations: Adj $R^{2}$, adjusted $R^{2}$; CGlobj, objective Clinical Global Impression; OCD, obsessive-compulsive disorder; SDS, Sheehan Disability Scale. 
shown in other studies. ${ }^{72-76}$ Other clinical treatment efficacy studies in OCD patients did not state comorbid personality disorders. Therefore, the present study is hard to compare with other studies. In two cross-sectional studies, however, comorbid personality disorders were present in a third to half of the patients, ${ }^{77,78}$ which is comparable to the present sample. In population studies, comorbid personality disorders were noted in $40 \%-70 \%$ of patients, depending on the type of assessment tools and population., ${ }^{7,79-81}$

The degree of dissociation measured with DES showed relatively high levels of psychological dissociative phenomena, with a mean score of $>18$, significantly exceeding an average score of $\sim 4$ in the general population; a score $>10$ may be considered pathological. ${ }^{71,82}$ Other authors also reported higher degrees of dissociation, but the mean DES scores varied considerably between studies. Prasko et al ${ }^{83}$ reported an average score of $13.11 \pm 13.75$ in OCD patients in Moravia, while Raszka et $\mathrm{al}^{71}$ found a score of $7.0 \pm 6.5$ in a Prague sample. The mean score in the latter study was in the normal range. The present study showed very high DES scores $(18.55 \pm 18.65)$, possibly reflecting the fact that the sample comprised treatment-resistant patients, as was the case in other studies. ${ }^{20,84-86}$

Patients who completed treatment showed significant improvement in all the assessment scales. Therapeutic improvement (S-Y-BOCS reduction of 35\%) and remission (CGI 1 or 2 ) were achieved in $64.9 \%$ and $49.1 \%$ of patients, respectively. The results corresponded with the results of pharmacological or CBT studies of treatment efficacy in OCD patients who achieved therapeutic improvement in 60\%-70\% and remission in $35 \%-50 \%$ of patients. ${ }^{87-94}$

The aim of the study was to determine whether it was possible to find predictors of therapeutic response to a comprehensive CBT program in OCD patients resistant to drug therapy. The age of OCD onset was not significantly correlated with the main indicators of change, ie, relative changes in S-Y-BOCS or CGIobj. Similarly, the age of disease onset did not influence the achievement of remission. The results of studies investigating the effect of age of disorder onset on treatment response are inconclusive. Some studies identified an earlier disease onset as a negative predictor of treatment efficacy, while others stated the opposite, claiming that treatment response was greater in patients with an early disease onset. ${ }^{95,96}$ Duration of the disorder did not play a role in the relative change of the main outcome measures, and neither did the employment status.

The present study showed no significant difference between those who achieved remission and those who did not in any demographic parameters such as age, duration of the disorder, beginning of the treatment, age of disease onset, years of education, insight, resistance, or even in generalized anxiety disorder initially evaluated with BAI. This is consistent with some other studies, which also found no such association. ${ }^{38,97}$ However, this finding is in contrast with studies suggesting that the duration of the disorder was negatively correlated with response to pharmacotherapy and psychotherapy. ${ }^{95}$

According to backward stepwise regression, the initial overall severity of the disorder evaluated with CGI proved to be the most significant factor contributing to the change in the severity of symptoms during treatment, which excluded other correlated factors, such as the degree of disability at work (SDS work/school), presence of depressive disorders, and the number of obsessive themes. According to the results of logistic regression, the initial severity of the disorder was also one of four factors contributing to achieving a remission, along with the initial BAI score, the number of obsessive themes, and the degree of insight. This finding is consistent with those in other studies, where the severity of OCD was a significant predictor of therapeutic outcome. ${ }^{32,38,95,98}$

It seems that the initial level of general anxiety is not a factor contributing to decreases in scores on the main outcome criteria. Similar findings were reported in a study by Steketee et al, ${ }^{99}$ where the initial level of anxiety did not predict the effect of CBT on OCD. However, if patients in the present study were divided according to the initial level of anxiety using a cut-off point of 25 in BAI, those with lower levels of anxiety at baseline achieved remission significantly more frequently. This factor was so significant that, according to binary logistic regression, other factors, such as the initial level of depression and comorbid depressive disorder, were excluded.

The severity of depression initially evaluated with BDI did not correlate with the relative change in S-Y-BOCS. When dividing the patients into two groups according to the severity of depressive symptoms, no difference in the main outcome criteria was observed. Thus, in contrast with the hypothesis formulated before the study, depressive symptomatology did not substantially influence the therapeutic effect. This is inconsistent with finding by Shetti et al, ${ }^{38}$ who showed that comorbid depressive disorder had an impact on treatment response. However, that was a 2-year follow-up of outpatients, while the present study assessed short-term intensive therapy. The present results are similar to those of a study by Steketee et al, ${ }^{99}$ where the initial level of depression did not predict the effect of CBT on OCD. 
The types of obsessions and compulsions were diverse in the present study, with predominant checking and fear of contamination. As for the proportion of responders, there were no statistically significant differences between patients with various types of OCD symptoms. However, there were a small number of patients with some types. For example, only four patients had a dominant theme of hoarding, and only five had sexual or religious obsessions. In many studies, however, certain types were poorly responsive to treatment, namely hoarding, and containing sexual, religious, magical content, and obsessional slowness. ${ }^{11,36,89,100}$

However, multiple obsessions made a difference. Patients with three or more themes achieved clinical response measured with CGIobj more often than those with one or two topics. The explanation can only be speculated upon, because such a finding has not been described in the literature. However, it appears that patients with multiple types of obsessions and compulsions may be more flexible to change. The number of themes is related to the degree of insight and the level of resistance to compulsion. Multiple topics proved to be such a significant factor for achieving remission that it was enforced until the last step in the binary logistic regression (along with the initial BAI, CGIobj, and insight).

Another examined phenomenon was the degree of dissociation. Psychological dissociation (assessed with DES) did not correlate with the outcome criteria of therapeutic change. A higher degree of psychological dissociation as a predictor of treatment response was found in several studies, ${ }^{20,85,86}$ while others failed to prove this relationship..$^{71,101}$

Interestingly, the degree of somatoform dissociation was significantly negatively correlated with the relative decrease of obsessions and compulsions in S-Y-BOCS. The higher the level of somatoform dissociation at baseline, the smaller was the change in OCD symptoms.

The degree of insight at the beginning of the treatment was significantly associated with a relative change in S-YBOCS. The greater the degree of insight, the greater the relative change in obsessions and compulsions. Backward stepwise regression analysis showed that the degree of insight was the most powerful predictor of the relative change of obsessive-compulsive symptomatology, which gradually excluded all other candidates, such as the level of somatoform dissociation, resistance to compulsions, initial Y-BOCSobj score, and initial BDI and CGIobj scores. Also in binary logistic regression analysis of various factors influencing the achievement of remission at the end of treatment, the degree of insight was among the four most important parameters, the others being BAI and CGIobj scores and the number of OCD themes. This finding has high clinical importance, suggesting an increase in the insight at the beginning of therapy.

Comorbidity with major depressive disorder did not affect the relative change in the main criteria of therapeutic outcome. Comorbid major depression, however, had a significant effect on the remission rate at the end of the treatment. Patients with major depressive disorder achieved remission less frequently, almost in half of the cases in comparison with those without depression. Comorbidity with anxiety disorder did not affect the therapeutic effect.

There was no impact of comorbid personality disorders on treatment efficacy. Both patients with and without personality disorders showed the same degree of improvement according to the main outcome criteria. The proportion of patients achieving therapeutic improvement in the group with personality disorders did not differ from that in the group without personality disorders, but the patients without personality disorder achieved remission significantly more often than patients without personality disorders. This finding is consistent with that in a study by Pigott and Seay. ${ }^{102}$

\section{Limitations of the study}

The study was limited by the relatively small number of patients included. This fact reduces the validity of the results and their generalization. Another limitation of the study was the coadministration of drugs with CBT, which made a determination of specific predictors for each of the treatment modalities impossible; thus only response to the comprehensive program could be evaluated. However, drugs were not significantly changed before and after the study, the only exception being reduction or discontinuation of benzodiazepines in five patients.

Another limitation of the study is the absence of a control group comprising either untreated (ideal for comparison, not so much for the patient) participants or those treated with drugs or an alternative program.

\section{Conclusion}

During the 6-week intensive CBT program in combination with pharmacotherapy, there was a significant improvement in patients suffering from OCD resistant to drug treatment. There were statistically significant decrease in scores assessing the severity of OCD symptoms, anxiety, and depressive feelings.

A lower treatment effect was achieved specifically in patients who showed fewer OCD themes in symptomatology, showed a higher level of somatoform dissociation, had 
poor insight, and had a higher initial level of overall severity of the disorder.

Remission of the disorder was more likely in patients who had good insight, a lower initial level of anxiety, and no comorbid depressive disorder.

\section{Disclosure}

The authors report no conflicts of interest in this work.

\section{References}

1. Hollander E, Kim S, Braun A, Simeon D, Zohar J. Cross-cutting issues and future directions for the OCD spectrum. Psychiatry Res. 2009; 170(1):3-6.

2. American Psychiatric Association. Diagnostic and Statistical Manual of Mental Disorders, Fifth Ed. DSM-5. Arlington: American Psychiatric Association; 2013.

3. Eisen JL, Goodman WK, Keller MB, et al. Patterns of remission and relapse in obsessive-compulsive disorder: a two-year prospective study. J Clin Psychiatry. 1999;60:346-351.

4. Steketee G, Henninger NJ, Pollard CA. Predicting treatment outcomes for obsessive-compulsive disorder: effects of comorbidity. In: Goodman WK, Rudorfer MV, Mase JD, editors. Obsessive-Compulsive Disorder: Contemporary Issues in Treatment. Mahwah, NJ: Lawrence Erlbaum Associates; 2000:257-274.

5. Nestadt G, Samuels J, Riddle MA, et al. The relationship between obsessive-compulsive disorder and anxiety and affective disorders: results from the Johns Hopkins OCD Family Study. Psychol Med. 2001; 31(3):481-487.

6. Yaryura-Obias MA, Pinto A, Neziroglu F. The integration of primary anorexia nervosa and obsessive-compulsive disorder. Eat Weight Disord. 2001;6:174-180.

7. Maina G, Albert U, Salvi V, Pessina E, Bogetto F. Early-onset obsessive-compulsive disorder and personality disorders in adulthood. Psychiatry Res. 2008;158(2):217-225.

8. Koran LM, Gamel NN, Choung HW, Smith EH, Aboujaoude EN. Mirtazapine for obsessive-compulsive disorder: an open trial followed by double-blind discontinuation. J Clin Psychiatry. 2005;66(4):515-520

9. Kaplan A, Hollander E. A review of pharmacologic treatments for obsessive-compulsive disorder. Psychiatr Serv. 2003;54(8): 1111-1118.

10. Abramowitz JS. Effectiveness of psychological and pharmacological treatments for obsessive-compulsive disorder: a quantitative review. J Consult Clin Psychol. 1997;65:44-52.

11. van Balkom AJ, de Haan E, van Oppen P, Spinhoven P, Hoogduin KA, van Dyck R. Cognitive and behavioral therapies alone versus in combination with fluvoxamine in the treatment of obsessive compulsive disorder. J Nerv Ment Dis. 1998;186(8):492-499.

12. Foa EB. Failure in treating obsessive compulsives. Behav Res Ther. 1997; 17:169-176.

13. Steketee G, Shapiro LJ. Predicting behavioral treatment outline for agoraphobia and obsessive-compulsive disorder. Clin Psychol Rev. 1995; 15:317-346.

14. Steketee G, Chambless DL, Tranm G. Effects of Axis I and II comorbidity on behavior therapy outcome for obsessive compulsive disorder and agoraphobia. Compr Psychiatry. 2011;42:76-86.

15. Salkovskis PM, Harrison J. Abnormal and normal obsessions: a replication. Behav Res Ther. 1984;22:549-552.

16. Praško J, Pašková $B$, Záleský R, et al. The effect of repetitive transcranial magnetic stimulation (rTMS) on symptoms in obsessive compulsive disorder. A randomized, double blind, sham controlled study. Neuroendocrinol Lett. 2006;27:327-332.

17. Basoglu M, Lax T, Kasvikis Y, Marks IM. Predictors of improvement in obsessive-compulsive disorder. J Anxiety Disord. 1988;2:299-317.
18. Bartlett AE, Drummond LM. Hysterical conversion and dissociation arising as a complication of behavioral psychotherapy treatment of obsessive-compulsive neurosis. Br J Med Psychol. 1990;63(2): $109-115$.

19. Goff DC, Olin JA, Jenike MA, Baer L, Buttolph ML. Dissociative symptoms in patients with obsessive-compulsive disorder. JNerv Ment Dis. 1992;180:332-337.

20. Rufer M, Held D, Cremer J, et al. Dissociation as a predictor of cognitive behavior therapy outcome in patients with obsessive-compulsive disorder. Psychother Psychosom. 2006;75:40-46.

21. Spitzer C, Barnow S, Freyberger HJ, Grabe HJ. Recent developments in the theory of dissociation. World Psychiatry. 2006;5:82-86.

22. March JS, Frances A, Carpenter D, Kahn D. Expert consensus guidelines: treatment of obsessive compulsive disorder. J Clin Psychol. 1997;58: $1-72$.

23. Cottraux J, Mollard E, Bouvard M, et al. A controlled study of fluvoxamine and exposure in obsessive compulsive disorder. Int Clin Psychopharmacol. 1990;5:17-30.

24. Cottraux J, Note I, Yao SN, et al. A randomized controlled trial of cognitive therapy versus intensive behavior therapy in obsessive compulsive disorder. Psychother Psychosom. 2001;70:288-297.

25. Foa EB, Sacks MB, Tolin DF, Prezworski A, Amir N. Inflated perception of responsibility for harm in OCD patients with and without checking compulsions: a replication and extension. J Anxiety Disord. 2002;16(4):443-453.

26. Foa EB, Liebowitz MR, Kozak MJ, et al. Randomized, placebocontrolled trial of exposure and ritual prevention, clomipramine, and their combination in the treatment of obsessive-compulsive disorder. Am J Psychiatry. 2005;162(1):151-161.

27. Kampman M, Keijsers GP, Hoogduin CA, Verbraak, MJ. Addition of cognitive-behaviour therapy for obsessive-compulsive disorder patients non-responding to fluoxetine. Acta Psychiatr Scand. 2002;106(4): 314-319.

28. Romanelli RJ, Wu FM, Gamba R, Mojtabai R, Segal JB. Behavioral therapy and serotonin reuptake inhibitor pharmacotherapy in the treatment of obsessive-compulsive disorder: a systematic review and meta-analysis of head-to-head randomized controlled trials. Depress Anxiety. 2014;31(8):641-652.

29. Kozak MJ, Foa EB, McCarthy PR. Assessment of obsessive-compulsive disorder. The NIMH-sponsored collaborative study. In: Goodman WK, Rudorfer MV, Maser JD, editors. Obsessive-Compulsive Disorder: Contemporary Issues in Treatment. Mahwah, NJ: Lawrence Erlbaum Associates; 1988:501-530.

30. Keeley ML, Storch EA, Merlo LJ, Geffken GR. Clinical predictors of response to cognitive-behavioral therapy for obsessive-compulsive disorder. Clin Psychol Rev. 2008;28(1):118-130.

31. Karno M, Golding JM, Sorensen SB, Burnam, MA. The prevalence of the obsessive-compulsive disorder in five US communities. Arch Gen Psychiatry. 1988;45:1094-1099.

32. Mataix-Cols D, Rauch SL, Manzo PA, Jenike MA, Baer L. Use of factor-analyzed symptom dimensions to predict outcome with serotonin reuptake inhibitors and placebo in the treatment of obsessivecompulsive disorder. Am J Psychiatry. 1999;156(9):1409-1416.

33. Saxena S, Maidment KM, Vapnik T, et al. Obsessive-compulsive hoarding: symptom severity and response to multimodal treatment. J Clin Psychiatry. 2002;63:21-27.

34. Pigott TA, L'Heureux F, Dubbert B, Bernstein S, Murphy DL. Obsessive compulsive disorder: comorbid conditions. J Clin Psychiatry. 1994;55: $15-27$.

35. Ravizza L, Barzega G, Bellino S, Bogetto F, Maina G. Predictors of drug treatment response in obsessive-compulsive disorder. J Clin Psychiatry. 1995;56(8):368-373.

36. Alonso P, Menchon JM, Pifarre J, et al. Long-term follow-up and predictors of clinical outcome in obsessive-compulsive patients treated with serotonin reuptake inhibitors and behavioral therapy. J Clin Psychiatry. $2001 ; 62: 535-540$. 
37. Hantouche EG, Bouhassira M, Lancrenon S. Prospective follow-up over a 12 month period of a cohort of 155 patients with obsessive-compulsive disorder: Phase III National DRT-TOC Study. Encephale. 2000; 26:73-83.

38. Shetti CN, Reddy YC, Kandavel T, et al. Clinical predictors of drug nonresponse in obsessive-compulsive disorder. J Clin Psychiatry. 2005; 66:1517-1523.

39. Saxena S, Brody AL, Maidment KM, Baxter LR Jr. Paroxetine treatment of compulsive hoarding. J Psychiatr Res. 2007;41:481-487.

40. Denys D, van Nieuwerburgh F, Deforce D, Westenberg HGM. Prediction of response to paroxetine and venlafaxine by serotonin-related genes in obsessive-compulsive disorder in a randomized, double-blind trial. J Clin Psychiatry. 2007;68:747-753.

41. Mezinárodní klasifikace nemocí. 10. revize. [International Classification of the Diseases - 10th edition] Duševní poruchy a poruchy chování: Diagnostická kritéria pro výzkum. (přeloženo z anglického originálu). Praha: Psychiatrické centrum; 1996. Czech.

42. Sheehan DV, Lecrubier Y, Sheehan KH, et al. The Mini-International Neuropsychiatric Interview (M.I.N.I.): the development and validation of a structured diagnostic psychiatric interview for DSM-IV and ICD-10. J Clin Psychiatry. 1998;59(suppl 20):22-33.

43. Amorim P. Mini International Neuropsychiatric Interview (MINI): brief interview validation for diagnosing mental disorders. Rev Bras Psiquiatr. 2000;22(3):106-115.

44. Pinninti NR, Madison H, Musser E, Rissmiller D. MINI International Neuropsychiatric Schedule: clinical utility and patient acceptance. Eur Psychiatry. 2003;18:361-364.

45. Goodman WK, Price LH, Rasmussen SA, et al. The Yale-Brown Obsessive Compulsive Scale. II. Validity. Arch Gen Psychiatry. 1989;46: 1012-1016

46. Goodman WK, Price LH, Rasmussen SA, et al. The Yale-Brown Obsessive Compulsive Scale. I. Development, use, and reliability. Arch Gen Psychiatry. 1989;46:1006-1011.

47. Raszka M, Praško J, Tintěra J, Horáček J. Depersonalizační a derealizační syndrom u pacientky s úzkostně depresivní poruchou v obraze 18FDG PET [Depersonalization and derealization syndrome in patients with anxiety-depressive disorder in the picture of 18FDG PET. Case report]. Kazuistika. Psychiatrie. 2009;13: 33-38. Czech

48. Guy W. ECDEU Assessment Manual for Psychopharmacology. Rockville: U.S. DHEW; 1976.

49. Zaider TI, Heimberg RG, Fresco DM, Schneier FR, Liebowitz MR. Evaluation of the Clinical Global Impression Scale among individuals with social anxiety disorder. Psychol Med. 2003;33:611-622.

50. Beck AT, Emery G. Anxiety Disorders and Phobias: A Cognitive Perspective. New York: Basic Books; 1985.

51. Beck AT, Epstein N, Brown G, Steer RA. An inventory for measuring clinical anxiety: psychometric properties. J Consult Clin Psychol. 1988; 56:893-897.

52. De Ayala, RJ, Vonderharr-Carlson DJ, Kim D. Assessing the reliability of the Beck Anxiety Inventory score. Educ Psychol Meas. 2005; 65:742-756

53. Magán I, Sanz J, García-Vera MP. Psychometric properties of a Spanish version of the Beck Anxiety Inventory (BAI) in general population. Span J Psychol. 2008;11(2):626-640.

54. de Beurs E, Wilson KA, Chambless DL, Goldstein, AJ, Feske U. Convergent and divergent validity of the Beck Anxiety Inventory for patients with panic disorder and agoraphobia. Depress Anxiety. 1997;6(4):140-146.

55. Beck AT, Steer RA, Ball R, Ranieri WF. Comparison of Beck depression inventories-IA and -II in psychiatric outpatients. J Pers Assess. 1996; 67(3):588-597.

56. Beck AT, Beamesderfer A. Assessment of depression: the depression inventory. Mod Probl Pharmacopsychiatry. 1974;7:151-169.

57. Preiss M, Vaciř K. Beckova sebeposuzovací škála depresivity pro dospělé - BDI-II [Beck self-report depression scale for adults - BDI-II]. Brno: Psychodiagnostika; 1999. Czech.
58. Bernstein EM, Putnam FW. Development, reliability, and validity of a dissociation scale. J Nerv Ment Dis. 1986;174:727-735.

59. Ptacek R, Bob P, Paclt I. Škála disociativních zkuseností - česká verze [Dissociative Experiences Scale - Czech version]. Cesk Psychol. 2006; 50(3):262-272.

60. Nijenhuis ERS, Spinhoven P, Van Dyck R, Van der Hart O, Vanderlinden J. The development and psychometric characteristics of the Somatoform Dissociation Questionnaire (SDQ-20). JNerv Ment Dis. 1996;184:688-694.

61. Farina B, Mazzotti E, Pasquini P, Nijenhuis E, Di Giannantonio M. Somatoform and psychoform dissociation among students. J Clin Psychol. 2011;67(7):665-672.

62. Sheehan DV, Harnett-Sheehan K, Raj BA. The measurement of disability. Clin Psychopharmacol. 1996;11(suppl 3):89-95.

63. Coles T, Coon C, DeMuro C, McLeod L, Gnanasakthy A. Psychometric evaluation of the Sheehan Disability Scale in adult patients with attention-deficit hyperactivity disorder. Neuropsychiatr Dis Treat. 2014;19(10):887-895.

64. Bonham CA, Uhlenhuth E. Disability and comorbidity: diagnoses and symptoms associated with disability in a clinical population with panic disorder. Psychiatry J. 2014;2014:619727.

65. Vigne P, de Menezes GB, Harrison BJ, Fontenelle LF. A study of poor insight in social anxiety disorder. Psychiatry Res. 2014;219(3): $556-561$.

66. Camuri G, Oldani L, Dell'Osso B, et al. Prevalence and disability of comorbid social phobia and obsessive-compulsive disorder in patients with panic disorder and generalized anxiety disorder. Int J Psychiatry Clin Pract. 2014;18(4):248-254.

67. Piane GM, Smith TC. Building an evidence base for the co-occurrence of chronic disease and psychiatric distress and impairment. Prev Chronic Dis. 2014;23(11):E188.

68. Praško J, Janů L, Junek P. Obsedantně kompulzivní porucha. In; Raboch J, Uhlikova P, Hellerova P, Anders M, Susta M (eds). Voditka léčebné péče-úzkostné a neurotické poruchy [Obsessive compulsive disorders. Guidelines for treatment care - anxiety and neurotic disorders]. Praha: Česká psychiatrická společnost; 2024:113-118. Czech.

69. Nakao T, Nakatani E, Nabeyama M, Yoshioka K, Tomita M, Nakagawa A. Duration effect on neuropsychological function and treatment response of OCD. Seishin Shinkeigaku Zasshi. 2005;107(12):1286-1298.

70. Koprrivová J, Congedo M, Horáček J, et al. EEG source analysis in obsessive-compulsive disorder. Neurophysiol Clin. 2011;122: 1735-1743.

71. Raszka M, Prasko J, Koprivova J, Novak T, Adamcova K. Psychological dissociation in obsessive-compulsive disorder is associated with anxiety level but not with severity of obsessive-compulsive symptoms. Neuroendocrinol Lett. 2009;30(5):624-628.

72. Belloch A, Del Valle G, Morillo C, Carrió C, Cabedo E. To seek advice or not to seek advice about the problem: the help-seeking dilemma for obsessive-compulsive disorder. Soc Psychiatry Psychiatr Epidemiol. 2009;44(4):257-264.

73. Demet MM, Deveci A, Taşkin EO, et al. Risk factors for delaying treatment seeking in obsessive-compulsive disorder. Compr Psychiatry. 2010;51(5):480-485.

74. Subramaniam M, Abdin E, Vaingankar JA, Chong SA. Obsessive compulsive disorder: prevalence, correlates, help-seeking and quality of life in a multiracial Asian population. Soc Psychiatry Psychiatr Epidemiol. 2012;47(12):2035-2043.

75. Wang X, Cui D, Wang Z, et al. Cross-sectional comparison of the clinical characteristics of adults with early-onset and late-onset obsessive compulsive disorder. J Affect Disord. 2012;136(3):498-504.

76. Vaingankar JA, Rekhi G, Subramaniam M, Abdin E, Chong SA. Age of onset of life-time mental disorders and treatment contact. Soc Psychiatry Psychiatr Epidemiol. 2013;48(5):835-843.

77. Pena-Garijo J, Edo Villamón S, Meliá de AlCba A, Ruipérez MÁ. Personality disorders in obsessive-compulsive disorder: a comparative study versus other anxiety disorders. Scientific WorldJournal. 2013;21: 856846 . 
78. Kampman M, Keijsers GP, Hoogduin CA, Hendriks GJ. A randomized, double-blind, placebo-controlled study of the effects of adjunctive paroxetine in panic disorder patients unsuccessfully treated with cognitive-behavioral therapy alone. J Clin Psychiatry. 2002;63(9): 772-777.

79. Weissman MM, Bland RC, Canino GJ, et al. The cross national epidemiology of obsessive compulsive disorder. J Clin Psychiatry. 1994;55(3 suppl):5-10.

80. Hollander E, Greenwald S, Neville D, Johnson J, Hornig CD, Weissman MM. Uncomplicated and comorbid obsessive-compulsive disorder in an epidemiologic sample. Depress Anxiety. 1996-1997;4(3): 111-119.

81. Torres AR, Moran P, Bebbington P, et al. Obsessive-compulsive disorder and personality disorder: evidence from the British National Survey of Psychiatric Morbidity 2000. Soc Psychiatry Psychiatr Epidemiol. 2006;41(11):862-867.

82. Pastucha P, Prasko J, Grambal A, Latalova K, Sigmundova Z, Tichackova A. Dissociative disorder and dissociation - comparison with healthy controls. Neuro Endocrinol Lett. 2009;30(6):769-773.

83. Prasko J, Raszka M, Diveky T, et al. Obsessive compulsive disorder and dissociation - comparison with healthy controls. Biomed Pap. 2010; 154(2):179-183

84. Lochner C, Seedat S, Hemmings SM, Moolman-Smook JC, Kidd M, Stein DJ. Investigating the possible effects of trauma experiences and 5-HTT on the dissociative experiences of patients with OCD using path analysis and multiple regression. Neuropsychobiology. 2007;56(1): 6-13.

85. Belli H, Ural C, Yesilyurt S, Vardart MK, Akbudak M, Oncu F. Childhood trauma and dissociation in patients with obsessive-compulsive disorder. West Indian Med J. 2013;62(1):39-44.

86. Semiz UB, Inanc L, Bezgin CH. Are trauma and dissociation related to treatment resistance in patients with obsessive-compulsive disorder? Soc Psychiatry Psychiatr Epidemiol. 2013;49(8):1287-1296.

87. Gava I, Barbui C, Aguglia E, et al. Psychological treatments versus treatment as usual for obsessive compulsive disorder (OCD). Cochrane Database Syst Rev. 2007;18(2):CD005333.

88. Lack CW. Obsessive-compulsive disorder: evidence-based treatments and future directions for research. World J Psychiatry. 2012;2(6): 86-90.

89. Knopp J, Knowles S, Bee P, Lovell K, Bower P. A systematic review of predictors and moderators of response to psychological therapies in OCD: do we have enough empirical evidence to target treatment? Clin Psychol Rev. 2013;33(8):1067-1081.

90. Pizarro M, Fontenelle LF, Paravidino DC, Yücel M, Miguel EC, de Menezes GB. An updated review of antidepressants with marked serotonergic effects in obsessive-compulsive disorder. Expert Opin Pharmacother. 2014;15(10):1391-1401.
91. Thompson-Hollands J, Edson A, Tompson MC, Comer JS. Family involvement in the psychological treatment of obsessive-compulsive disorder: a meta-analysis. J Family Psychol. 2014;2(3):287-298.

92. Bystritsky A, Ackerman DL, Rosen RM, et al. Augmentation of serotonin reuptake inhibitors in refractory obsessive-compulsive disorder using adjunctive olanzapine: a placebo-controlled trial. J Clin Psychiatry. 2004;65(4):565-568.

93. Storch EA, Goddard AW, Grant JE, et al. Double-blind, placebocontrolled, pilot trial of paliperidone augmentation in serotonin reuptake inhibitor-resistant obsessive-compulsive disorder. J Clin Psychiatry. 2013;74(6):e527-e532.

94. O'Neill J. Augmentation with cognitive behavioural therapy has superior efficacy to augmentation with risperidone for treating adults with treatment-resistant OCD. Evid Based Ment Health. 2014;17(2) $58-59$.

95. Dell'Osso B, Benatti B, Buoli M, et al. The influence of age at onset and duration of illness on long-term outcome in patients with obsessive-compulsive disorder: a report from the International College of Obsessive Compulsive Spectrum Disorders (ICOCS). Eur Neuropsychopharmacol. 2013;23(8):865-871.

96. Visser HA, van Oppen P, van Megen HJ, Eikelenboom M, van Balkom AJ. Obsessive-compulsive disorder; chronic versus nonchronic symptoms. J Affect Disord. 2014;15(2-154):169-174.

97. Olatunji BO, Rosenfield D, Tart CD, Cottraux J, Powers MB, Smits JA Behavioral versus cognitive treatment of obsessive-compulsive disorder: an examination of outcome and mediators of change. J Consult Clin Psychol. 2013;81(3):415-428.

98. Mataix-Cols D, Boman M, Monzani B, et al. Population-based, multigenerational family clustering study of obsessive-compulsive disorder. JAMA Psychiatry. 2013;70(7):709-717.

99. Steketee G, Siev J, Fama JM, Keshaviah A, Chosak A, Wilhelm S. Predictors of treatment outcome in modular cognitive therapy for obsessive-compulsive disorder. Depress Anxiety. 2011;28(4): 333-341

100. Eisen JL, Sibrava NJ, Boisseau CL, et al. Five-year course of obsessivecompulsive disorder: predictors of remission and relapse. J Clin Psychiatry. 2013;74(3):233-239.

101. Shavitt RG, Valério C, Fossaluza V, et al. The impact of trauma and post-traumatic stress disorder on the treatment response of patients with obsessive-compulsive disorder. Eur Arch Psychiatry Clin Neurosci. 2010;260(2):91-99.

102. Pigott TA, Seay S. Pharmacotherapy of obsessive-compulsive disorder. Int Rev Psychiatry (Abingdon, England). 1997;9:133-147.
Neuropsychiatric Disease and Treatment

\section{Publish your work in this journal}

Neuropsychiatric Disease and Treatment is an international, peerreviewed journal of clinical therapeutics and pharmacology focusing on concise rapid reporting of clinical or pre-clinical studies on a range of neuropsychiatric and neurological disorders. This journa is indexed on PubMed Central, the 'PsycINFO' database and CAS,

\section{Dovepress}

and is the official journal of The International Neuropsychiatric Association (INA). The manuscript management system is completely online and includes a very quick and fair peer-review system, which is all easy to use. Visit http://www.dovepress.com/testimonials.php to read real quotes from published authors. 